\title{
Stress e Qualidade de Vida em Magistrados da Justiça do Trabalho: Diferenças entre Homens e Mulheres
}

\author{
Marilda E. Novaes Lipp ${ }^{1}$ \\ M. Sacramento Tangandli \\ Pontifícia UniversidadeCatólica deCampinas
}

\begin{abstract}
Resumo
O stress ocupacional é tema freqüente nas pesquisas atuais. Averiguou-se o stress ocupacional de Magistrados da Justiça do Trabalho, níveis de qualidade de vida, fontes de stress e estratégias de enfrentamento. Setenta e cinco juízes completaram cinco inventários, enviados através da associação de classe. 0 grupo avaliou seu stress ocupacional como nível 8 em uma escala de 0 a 10. Verificou-se que $71 \%$ dos juízes apresentavam sintomas de stress. Havia mais mulheres com stress do que homens. Qualidade de vida mostrou-se comprometida nas áreas social, afetiva, profissional e da saúde. Os estressores mais freqüentes foram sobrecarga de trabalho e interferência com a vida familiar. A estratégia mais mencionada foi conversar com o cônjuge. Resultados são discutidos em termos dos possíveis efeitos negativos para os indivíduos nesta classe ocupacional e no processo judicional.

Palavras-chave: Stress ocupacional; juízes; qualidade de vida.
\end{abstract}

\section{Stress and Quality of Life in Judges who deal with Labor Relations: Differences in Gender}

\begin{abstract}
Occupational stress is a frequent theme at present. Occupational stress in Brazilian judges in charge of labor -related cases, quality of life, work-related stressors and coping strategies were investigated. Seventy-five judges answered five instruments sent to them through the class association. They rated the perceived occupational stress level as 8 on a rating scale of 0 to 10 . It was found that $71 \%$ of them and that more women had stress symptoms. Quality of life was deficient in social, professional, affective and health related areas. The most stressful aspects of work were backlog of cases and interference with family life. The most common coping strategy reported was to talk with spouse. Results are discussed in terms of possible adverse effects on the individuals in this occupational class and also on the judging process.

Keywords: Occupational stress; judges; quality of life.
\end{abstract}

Os mecanismos de ação do stress no funcionamento humano têm recebido a atenção de pesquisadores em nível internacional (Everly, 1995; R. S. Lazarus \& B. N. Lazarus, 1994; Wright \& Cropanzano, 2000) queidentificaram conseqüênciasnegativasno funcionamento físico (Di Martino, 1992; Mancia \& Parati, 1987) e no mental (Myers, 1995; Teicher, Ito, Glod, Schiffer \& Gelbard, 1996), na medida em que o stress pode contribuir para a ontogênese de várias doenças físicas epsiquiátricas. Há também indicação deque um estado prolongado de stresspossa interferir com o bemestar psicológico e a qualidade de vida das pessoas (Kaplan, 1995; Lipp, 1997).

As pesquisas na área de stress têm incluído o estudo dos efeitos negativos do stress no que se refereà profissão. Muitas ocupações têm recebido atenção, sendo que, no Brasil, já se encontram trabalhos sobre o stress ocupacional de policiais militares (Romano, 1989), executivos (Soares, 1990), de psicólogos (Covolan, 1989), bancários (Silva, 1992), atletas (Maciel, 1997), professores (Reinhold, 1997),

\footnotetext{
${ }^{1}$ Endereço para correspondência: Rua Tiradentes, 289/91, 13023-190, Campinas, SP. Fone: (19) 32430288. E-mail: mlipp@estresse.com.br
}

jornalistas (Proença, 1998), médicos (Lipp, Sassi \& Batista, 1997) entre outros. No entanto, pouco se conhece do stress em juízes. 0 número de estudos nesta área é mínimo e a maioria se refere à realidade americana. Por exemplo, Showalter e Martell (1985) estudaram características da personalidade de juízes, Zimmerman (1981) analisou o conflito enfrentado pelos juízes gerado pelo que seria 0 ideal em um caso e a realidade da esfera legal e Eells e Showalter (1994) analisaram o nível de stress em juízes de tribunal e seu impacto na habilidade de tomar decisões judiciais. No Canadá, Rogers, Freeman e LeSage (1991) publicaram o primeiro levantamento sistemático sobre 0 stress ocupacional de juízes naquele país e identificaram a solidão e isolamento da atividade judicante como uma das maiores fontes de stress na profissão. No Brasil, encontra-se o trabalho de Vianna, Carvalho, Melo e Burgos (1997) intitulado "Corpo e alma da magistratura brasileira" que, embora não direcionado para o estudo do stress, revela várias características e fontes de stress na Magistratura.

A atividade judicante encontra-se entre as mais conceituadas e respeitadas universalmente, mas ao mesmo tempo, ela envolve uma responsabilidade de grande 
monta pelo seu impacto na sociedadeno geral euma solidão pronunciada que envolve 0 ato de julgar. A estes fatores, acrescentam-se uma carga grande de processos a serem julgados e o peso emocional do julgamento, além das expectativas da comunidade quanto a um comportamento e um viver absolutamente exemplar por parte das pessoas que a exercem. 0 próprio ato de julgar já foi identificado por Rogers e colaboradores (1991) como um estressor de grande impacto. No que se refere à sobrecarga dos processos, Zimmerman (1981) verificou em uma pesquisa queenvolveu entrevistas extensas com juízes americanos que quando os processos a serem julgados se acumulam, surge uma sensação de falta de controle, desalento e angústia mesmo nos mais competentes e dedicados dos juízes.

O stress pode ser definido como uma reação muito complexa, composta de alterações psicofisiológicas que ocorrem quando o indivíduo é forçado a enfrentar situações queultrapassem sua habilidade de enfrentamento (Lipp, 1997). A função destas respostas é a adaptação do indivíduo à nova situação, gerada pelo estímulo desafiador. O stress pode produzir efeitos negativos como a fadiga, tensão muscular que podem aparecer não só quando ocorre uma experiência trágica, como a morte de algum amigo ou parente, mas também em outras situações diversas, como mudanças de emprego, trabalho com excesso de tarefas que devem ser realizadas em curto espaço de tempo, pressão constanteno trabalho, exigências ocupacionais exageradase outros fatores (Everly, 1995). A natureza do estressor pode ser negativa, como perdas ou dificuldades familiares ou positiva, como um reconhecimento profissional, um aumento salarial, conformemencionado por Selye (1956) e Holmes e Rahe (1967). O que determina se sintomas de stress vão ocorrer é a capacidade do organismo de atender às exigências do momento, independentementedestas serem de natureza positiva ou negativa. A resistência aos desafios enfrentadosétambém influenciada consideravelmentepelas estratégias de enfrentamento, ou coping, presentes no repertório da pessoa. Folkman eLazarus (1988), Nacaratto (1995), Savoia, Santana e Mejias (1996) e Zakir (2001) tem enfatizado o conceito de oping como fator mediador entre 0 estímulo desafiador e o desenvolvimento da reação do stress. Antoniazzi, Dell' Aglio e Bandeira (1998) fazem uma revisão sobre o conceito de coping, que mostra a necessidade de se considerar a mediação defatores internos na ação de eventos os quais podem ser interpretados como estressantes ou não por pessoas diferentes.

O processo do stress se divide em três fases: alerta ou alarme, resistência e exaustão, sendo que os sintomas se diferenciam dependendo da seriedade do stress. Pesquisadores mencionam inúmeras complicações que podem surgir como parte de reações a situações estressantes: arteriosclerose, distúrbios no ritmo cardíaco, enfarte e derrame cerebral. Outras doenças que podem ocorrer em função do stress são diabetes, câncer (em face de diminuição da imunidade), úlceras, gastrites, doenças inflamatórias, colites, problemas dermatológicos (micoses, psoríase, queda decabelo), problemas relacionados à obesidadeeproblemas sexuais como impotência e frigidez entre outros. Além das patologias físicas e mentais que podem ocorrer, há também uma queda na habilidade de se concentrar e de pensar de modo lógico com conseqüente queda de produtividade.

Lipp, Romano, Covolan eNery (1986) eFontana (1991) descrevem os efeitos do stress excessivo na produtividade: ocorre um decréscimo da concentração e atenção aumentando a desatenção diminuindo os poderes de observação. As memórias de curto e longo prazo deterioram-se, reduzindo-se a sua amplitude e 0 reconhecimento, mesmo de aspectos familiares, diminui. A velocidade da resposta torna-se imprevisível, aumentam os índices de erros, perdem-se os poderes de organização e 0 planejamento em longo prazo. Aumentam as tensões e os distúrbios de pensamento. Ocorrem mudanças nos tracos de personalidade e crescem os problemas já existentes. Enfraquecem-se as restrições de ordem moral e emocional e aparecem a depressão e a sensação de desamparo. A autoestima diminui. Adicionalmente, podem aumentar ou aparecer os problemas de articulação verbal, diminuir o interesse e o entusiasmo pelo trabalho, aumentando 0 número de faltas. Os níveis de energia ficam reduzidos, rompem-se os padrões de sono e o uso de drogas pode se instalar. É comum ocorrer o cinismo em relação aos colegas ou a própria clientela e uma tendência a ignorar novas informações resolvendo os problemas de forma cada vez mais superficial.

Além disto, o desgaste causado pelo stress pode levar a pessoa ao estado de burnout termo popular nos Estados Unidos, nos últimos 10 anos, que descreve uma realidade de stress crônico em profissionais cujas atividades exigem um alto grau de contato com as pessoas (Perlman \& Hartman, 1982). É caracterizado por sintomas e sinais de exaustão física, psíquica e emocional que ocorrem quando astarefasintelectuais exigem grande qualificação intelectual, decisões importantes e têm um peso emocional muito intenso (França, 1987).

A relação entre stress e qualidade de vida tem recebido atenção dos pesquisadores brasileiros, como Curcio (1991), Malagris (1992) eSilva (1992). Qualidadedevidaéum estado de bem-estar físico, mental e social e não só a ausência de doenças. As pessoas que se consideram felizes atribuem sua felicidade ao sucesso em quatro áreas (social, afetiva, saúde e profissional). O stress ocupacional, segundo Couto (1987), interfere na qualidade devida modificando a maneira como 
o indivíduo interage nas diversas áreas da sua vida. Dessa forma, na área familiar pode ocorrer alta incidência de desajustamentos. O pouco tempo dedicado à família em função do alto investimento no trabalho acarreta a falta de suporte e apoio quando necessário. Na área social, podem ocorrer o isolamento e a conseqüente falta de amigos. Culturalmente, pode ocorrer rigidez comprometedora do desempenho em função da grande resistência a mudanças desenvolvida. A criatividade fica prejudicada e um empobrecimento de valores pode ocorrer, principalmente se a pessoa assume uma forte tendência a buscar ou a se manter no poder.

Torna-se claro que os efeitos do stress excessivo econtínuo não se limitam ao comprometimento da saúde. 0 stress pode, além de ter um efeito facilitador no desenvolvimento deinúmeras doenças, propiciar um prejuízo paraa qualidade de vida e a produtividade do ser humano, o que gera um interesse grande pelas causas e pelos métodos de redução do stress

Segundo Lipp (1984), o stress pode ser originado de fontes externas e internas. As fontes internas estão relacionadas com a maneira de ser do indivíduo, tipo de personalidade e seu modo típico de reagir à vida. Muitas vezes, não é o acontecimento em si que possa ser estressante, mas a maneira como é interpretado pela pessoa. Os estressores externos podem estar relacionados com as exigências do dia-a-dia do indivíduo como os problemas de trabalho, familiares, sociais, morte ou doenças de um filho, perda de uma posição na empresa, não concessão deum objetivo detrabalho, perda de dinheiro ou dificuldades econômicas, notícias ameaçadoras, assaltos eviolências das grandes cidades, etc. Muito freqüentemente, o stress ocorre em função da ocupação que a pessoa exerce.

Kyriacow e Sutcliffe (1981) definem o stress ocupacional como um estado emocional desagradável, pela tensão, frustração, ansiedade, exaustão emocional em função de aspectos do trabalho definidos pelos indivíduos como ameaçadores. O stress ocupacional agrava-se quando há por parte do indivíduo a percepção das responsabilidades e poucas possibilidades de autonomia e controle. As dificuldades em adaptar-se a essas situações levam ao stress. Dessa forma, a adaptação de um indivíduo a uma nova situação requer um investimento de recursos que vai depender do seu tipo de comportamento, suas crenças e expectativas frente ao mundo.

Para Albrecht (1988), os estressores podem ser classificados em três fatores, na situação de trabalho: físicos, sociais e emocionais. Para R. S. Lazarus e B. N. Lazarus (1994), a sobrecarga de trabalho, causada pela designação de muitas tarefas com prazos curtos para sua execução, e com muitas interrupções, a ambigüidade de prioridades, o nível de autoridade e de autonomia, a incerteza quanto ao futuro, o convívio com colegas insatisfeitos são fatores estressantes relacionados ao stress ocupacional.

No que se refere às fontes de stress identificadas nos juízes, os poucos trabalhos existentesnos EUA eno Canadá apontam para fatores como: sobrecarga de processos (Zimmerman, 1981), solidão do ato de julgar (Rogers \& cols., 1991), conflitos entre valores profissionais e pessoais (Eells \& Showalter, 1994) e determinadas características de personalidade(Showalter \& Martell, 1985; Suran, 1982). Nenhum trabalho foi encontrado enfocando especificamente as fontes de stress ocupacional do juiz brasileiro.

A carreira de juiz é especialmente difícil, por exigir muitos sacrifícios de ordem pessoal e uma clareza das limitaçõesimpostas. Por outro lado, o juiz não se mantém indiferente eimperturbável diantedos múltiplos problemas e situações que se lhe apresentam. O juiz, no seu papel de intérprete e distribuidor de justiça, deve ter a permanente preocupação de bem aferir as desigualdades sociais, o que pode gerar um considerável nível de stress (Zimmerman, 1981).

\section{Perfil do Magistrado Brasileiro}

Vianna e colaboradores (1997) traçaram o perfil do juiz brasileiro como se descreve a seguir. No Brasil, a idade média dos juízes concursados em atividade é de 42,4 anos. As diferenças no perfil etário da magistratura são significantes quando considerados alguns Estados. Rio Grande do Sul, São Paulo e Pernambuco têm, respectivamente, $51 \%$, $54 \%$ e $56 \%$ dos juízes com até 40 anos de idade, distinguindo-se do Rio de Janeiro, cujo índice é de cerca de 33,7\%. A Justiça Federal e a Justiça do Trabalho apresentam um perfil etário mais jovem. Quanto à participação feminina, as regiões Norte e Sul assinalam índices superiores a 20\%, sendo que o Rio de Janeiro conta com cerca de $30 \%$ de mulheres nos quadros da magistratura.

No que diz respeito à formação universitária, a idade média de ingresso no curso de Direito é de 21,8 anos, situando-se a mediana em 25 anos. A duração média do curso é de 5,3 anos. Observa-se, ainda que a trajetória universitária do magistrado ésignificativamente dependente de suas origens familiares: o ingresso tardio no curso de Direito associa-se a um perfil familiar de escolaridade mais baixa e de ocupações menos qualificadas. Com relação ao ingresso na magistratura, o intervalo médio entrea graduação em Direito e o concurso à magistratura é de 5,9 anos, situando-se a mediana em 5 anos. Este fato sugere que a opção pelo concurso público é majoritariamente precoce, 
observando-se, ainda, uma tendência ao ingresso maisrápido na magistratura entre aqueles que se graduaram mais cedo.

A trajetória típica de um juiz inclui a passagem por um período probatório de 2 anos - em geral, em juízo único, antes de adquirir vitaliciedade. No estágio inicial de sua carreira, o juiz experimenta uma significativa mobilidade: cerca de $60 \%$ dos magistrados permaneceram um tempo inferior a 5 anos no órgão em que adquiriram vitaliciedade. Quanto ao tempo depermanência na carreira, $71,9 \%$ dosjuízes aposentados à época da pesquisa exerceram suas atividades por mais de 10 anos, com um tempo médio de 17,6 anos.

O juiz de primeiro grau da Justiça Comum - bem como dos demais ramos da Justiça - inicia sua carreira como juiz não vitalício, cumprindo um período probatório de 2 anos, usualmente em uma comarca de menor importância situada no interior do estado. Nessas condições, ele se encontra exposto a uma multiplicidade temática, exercendo judicatura penal, cível, administrativa, e, em alguns casos menos freqüentes, matérias federal e trabalhista - 65,5\% dos juízes adquiriram vitaliciedade em juízos únicos, onde são jul gados feitos de toda natureza. Sua confirmação como juiz vitalício depende, pelo menos em tese, da aferição do seu bom desempenho durante esses dois primeiros anos de atividade. Especialmente nessas pequenas comarcas, mais do queviver um processo solitário em que ele internaliza os papéis descritos eesperados da sua profissão, o juiz tem a sua experiência dramatizada pelo desenraizamento epelo isolamento cultural esocial - 49,4\% adquiriram vitaliciedade em comarcas de primeira estância. Para os juízes de segundo grau concursados, o tempo médio de permanência como juiz vitalício de primeiro grau situase em 16,3 anos.

Há uma elevada mobilidade no início da carreira do magistrado, cujo primeiro patamar o retém por muito pouco tempo, ao estilo da carreira militar. 0 juiz transita rapidamentepelos estágiosiniciais da carreira, permanecendo estacionado por um longo período nas principais estâncias, aguardando uma eventual promoção para os tribunais de segundo grau. A grande concentração dosjuízes no patamar intermediário da carreira consisteem um elemento estrutural que tenciona o sistema, incentivando entre eles uma competição, cujas regras se tornam evidentes apenas quando o critério de promoção está referido à antigüidade.

A dinâmica detrabalho dosjuízes, profissionaiscuja rotina implica em excesso de tarefas com tempo escasso para a sua realização, responsabilidade por estar diante de tomada de decisões sobre a vida do outro efalta dereconhecimento são alguns do estressores que podem comprometer a saúde física e psicológica se estratégias adequadas e suficientes não forem utilizadas.
Os poucos estudos encontrados na área do stress ocupacional de juízes além de se referirem a outros países, abrangem todos os tipos de juízes, não averiguando as diferenças entre as várias funções por eles exercidas. Por exemplo, não se encontrou nenhum estudo que especificamente abordasse o stress do Magistrado do Trabalho.

A presente pesquisa visou suprir esta lacuna estudando o stress ocupacional de juízes do trabalho no Brasil. Os objetivos principais foram averiguar a incidência e sintomatologia de stress bem como o nível de qualidade de vida nas áreas social, saúde, profissional e afetiva de Magistrados do Trabalho. Adicionalmente, pesquisou-se as fontes de stress relacionadas a atividade judicante para melhor seconhecer as variáveis que possam vir a ocasionar dificuldades nesta classe ocupacional. Investigaram-se também as estratégiasmais tipicamenteutilizadasporjuízes do trabalho em uma tentativa natural de lidar com 0 stress excessivo.

\section{Método}

\section{Participantes}

A amostra foi composta por 75 Magistrados da Justiça do Trabalho da $15^{\mathrm{a}}$ Região que aceitaram participar anonimamente da pesquisa. Este número representa um retorno espontâneo de 53\% dentre os 140 Magistrados para quem os questionários foram enviados, não tendo havido qualquer insistência adicional por parte da Associação dos Magistrados da Justiça do Trabalho da 15. Região (AMATRA XV) quanto à devolução dos instrumentos, além da solicitação inicial.

\section{Materiais e Instrumentos}

A coleta de dados utilizou um questionário de identificação elaborado com a finalidade de se obter informações gerais sobre os participantes como o sexo, estado civil, tempo de profissão, cargo ocupado, dados do cônjuge e filhos. Incluía também uma questão sobrea fase da carreira quando o stress foi percebido como mais intenso e solicitava-se que incluíssem outros dados que eles considerassem relevantes. O nível de stress e sua sintomatologia foram avaliados através do uso do Inventário de Sintomas de Stress (ISS) elaborado com base nos conceitos de Selye e validado por Lipp e Guevara (1994). O ISS é composto de três quadros cada um se referindo a uma das fases do processo de stress, de acordo com o modelo trifásico de Selye (1956). Permite avaliar os sintomas de stress tanto ao nível cognitivo como ao nível somático e possibilita ainda identificar a fase de stress em que o indivíduo se encontra. O respondente é solicitado a indicar se tem tido o sintoma de stress 
especificado em cada quadro em 24 horas, 1 semana ou 1 mês. Os dois primeiros quadros, que se referem às fases de alarme e resistência respectivamente, contam com 15 itens cada e o terceiro quadro, que permite o diagnóstico do stress já em fase de exaustão, possui 23 itens. A avaliação é feita em termos das tabelas percentuais do teste.

A fim deverificar qual a percepção que osjuízes tinham quanto ao stressocupacional que o exercício da Magistratura do Trabalho envolve, foi solicitado que cada respondente desse uma nota de 1 a 10, sendo 10 a nota indicadora de "Extremamente estressante" e 1 "Pouco estressante" ao stress ocupacional da sua atividade. Esta escala deavaliação do stress foi utilizada pelo Instituto deCiência eTecnologia da Universidade de Manchester em 1992 em um estudo que comparou 19 profissões quanto ao nível de stress ocupacional envolvido em cada uma (University of Manchester, 1987).

O Inventário deQualidadedeVida (IQV), publicado por Lipp e Rocha em 1995, foi utilizado com o objetivo de identificar indicadores do nível de qualidade de vida dos participantes. O IQV é composto por questões referentes a aspectos da vida referentes aos quadrantes: profissional, saúde, social e afetivo. 0 conjunto de respostas dadas aos quadrantes indica o nível de qualidade de vida da pessoa avaliado pela presença de indicadores de problemas nestas áreas de funcionamento. Não pretendeidentificar a presença real de doenças, mas sim de indicadores que poderiam eventualmente contribuir para o desenvolvimento de problemas de saúde. Verifica, por exemplo, se a pessoa faz ou não relaxamento regularmente; se pratica esportes com regularidade e se consume uma alimentação saudável.

A fim de se identificar as causas do stress ocupacional do grupo, utilizou-se o Inventário de Fontes de Stress de Juízes (IFSJ), que aparece no Anexo A, especialmente elaborado para esta pesquisa com base em um estudopiloto do qual fizeram parte 4 juízes As principais fontes de stress por eles mencionadas foram relacionadas a dificuldades na vida familiar em função das exigências do trabalho, a sobrecarga, a falta do reconhecimento do seu trabalho e a dificuldades no relacionamento com os colegas de trabalho. As respostas foram então classificadas em categorias de eventos segundo a área das dificuldades apontadas. Entre eles citam-se os eventos econômicos; eventos que indicam insegurança, eventos que envolvem sentimentos de impotência e fracasso, eventos ligados ao relacionamento no trabalho, e outros.

Como parte do estudo-piloto, coletou-se dados que permitiram a elaboração do instrumento Inventário de Estratégias de Manejo do Stress dos Magistrados (IESM) utilizado. O IESM foi também baseado nos conceitos de Girdano e Everly (1979) quanto às estratégias de enfrentamento. Algumas das estratégias utilizadas segundo as respostas dos participantes foram: "peço ajuda a Deus, converso com o cônjuge, pratico exercícios físicos, vou ao cinema", entre outras.

\section{Procedimentos}

Cento e quarenta juízes, dos quais 75 responderam, foram contatados por carta enviada pela Associação dos Magistrados da Justiça do Trabalho da $15^{a}$ Região (AMATRA XV) na qual o presidenteda associação solicitava a colaboração dosjuízes em responderem aos questionários. Uma carta das pesquisadoras foi incluída explicando os objetivos da pesquisa e fornecendo informações sobre 0 sigilo e a liberdade em optar pela participação ou não no estudo. Os instrumentos que compõem a bateria de testes organizada especificamentepara a avaliação do nível destress do juiz do trabalho foram anexados. Os inventários foram enviados à AMATRA XV em envelopes fechados para serem preenchidos e, posteriormente, devolvidos fechados às pesquisadoras, sendo depois analisados. Deste modo, somente as pesquisadoras e sua equipe tomaram contacto com as respostas dos participantes o que garantiu o sigilo das respostas.

\section{Resultados e Discussão}

\section{Análisededados}

Primeiramente, a amostra foi caracterizada em termos percentuais quanto a sexo, idade, estado civil, número de filhos e tempo de exercício de Magistratura. O período do exercício da ocupação considerado mais estressante foi analisado em percentagens dos que indicaram cada período de tempo como mais tenso. Os dados coletados foram analisados também percentualmente quanto à prevalência do stress e qualidade de vida entre os respondentes em geral e por sexo. O teste t foi utilizado para analisar as diferenças quanto ao stress de juízes por sexo ea prova do Qui quadrado foi aplicada para se avaliar o nível de associação entre sintomas de stress e níveis de qualidade de vida. Um nível de significância de $\mathrm{p}=0,05$ foi pré-determinado.

\section{Caracterização da amostra}

Cinqüenta etrês por cento dos magistrados contatados responderam à solicitação para participarem da pesquisa. Este índice de resposta pode ser considerado satisfatório considerando-se que esta classe ocupacional possui uma quantidade grande de processos aos quais necessita analisar dentro de prazos determinados, o que poderia interferir com a disposição para responder aos vários questionários da pesquisa. A análise dos dados revelou que a amostra 
espontânea era constituída de 51\% de mulheres e 49\% de homens com $47 \%$ do total na faixa etária entre 30 e 39 anos. Embora esta predominância tenha sido encontrada tanto parajuízes de um sexo como do outro, identificou-se mais mulheres com menos de 29 anos, ou seja, 18\% de mulheres e $11 \%$ dehomens. Revelando uma tendência mais recente da entrada de mulheres na Magistratura, como já encontrado por Vianna e colaboradores, em 1997. Somente $12 \%$ da amostra total tinham mais de 50 anos, revelando o rejuvenescimento da Magistratura. No que se refere ao estado civil, 57 dos 75 respondentes eram casados, notando-se uma incidência de somente quatro divorciados na amostra, sendo trêsmulheres e um homem. Sessenta e três por cento da amostra total haviaingressado na Magistratura hámenos de 5 anoseapenas 11\% há mais de 10 anos o que se explica pelaidade bastante jovem da maioria dos respondentes. Quarenta e um por cento dosjuízes estavam casados há mais de 10 anos etinham dois filhos. Do total, 30\% residia com mais três pessoas em casa e somente um juiz residia sozinho.

\section{Época demaior stress}

Quase metade da amostra considerou que o primeiro ano do exercício da carreira havia sido a mais estressante, $31 \%$ considerou que o stress ocupacional do juiz tem caráter cíclico e $20 \%$ alegou que o stress tende a se acumular, aumentando com o tempo. O alto nível de stress experimentado no primeiro ano aponta para a necessidade de umamelhor iniciação edeapoio dos colegasmais experientes no início da carreira de Magistrado da Justiça do Trabalho. O caráter cíclico e cumulativo do stress através dos anos torna clara a necessidade de um treinamento especializado no manejo do stress que possa evitar o impacto aversivo do stress em uma população tão jovem e de tanta responsabilidade perante a sociedade.

\section{Percepção do stressocupacional}

A média da nota aferida pelos juízes à sua atividade profissional, no geral, foi a de 8 com desvio-padrão de 2 , indicando que o grupo considera o exercício da atividade da Magistratura do Trabalho como altamente estressante. A nota de 8,3 aferida pelos juízes foi semelhante a que 0 estudo do Instituto deCiência eTecnologia da Universidade deManchester (University of Manchester, 1987) obtevepara as pessoas que trabalham em minas $(8,3)$, maior do que a de policiais $(7,5)$, piloto de avião $(7,5)$ e bombeiros $(6,3)$.

Indidênàa destressesintomatologia maisfreqüente

A Figura 1 mostra as percentagens de juízes com e sem stress podendo-se verificar que aproximadamente $71 \%$ da amostra apresentavam sintomatologia típica de um quadro de stress. Observe-se também que 1,3\% se encontravam na fase de exaustão do stress, que é a fase mais adiantada quando doenças graves já estão presentes. Somente $29 \%$ não tinham sintomas de stress. A incidência de stress nos juízes do trabalho foi a mais alta encontrada nas pesquisas nacionais sobre o stress ocupacional, quando se compara policiais militares com 65\% (Romano, 1997); jornalistas com 62\% (Proença, 1998), enfermeiras com 60\% (Villar, 1992) e executivos com $41 \%$ (Proença, Bortoletto \& Lipp, 1996). O alto nível de stressencontrado confirma a avaliação realizada pelos próprios juízes quanto ao fato de ser a profissão altamente estressante, comparando-se com dados da literatura internacional com o stress de trabalhadores de minas e maior do que o de pilotos de avião (University of Manchester, 1987).

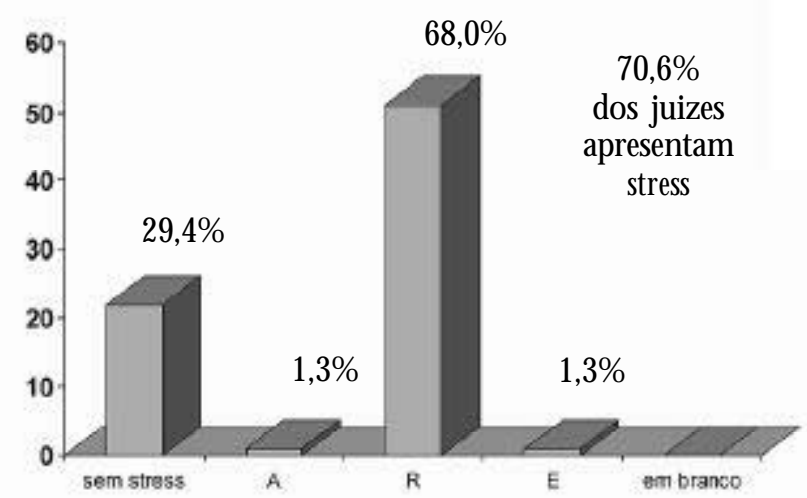

Figura 1. Incidência de stress.

A avaliação dos sintomas mais freqüentemente mencionados pelos juízes revelou que $71 \%$ deles tinham uma sensação de desgaste físico constante, $60 \%$ sofriam de tensão muscular e 52\% apresentavam irritabilidade excessiva. Considerando-se as exigências habitualmente colocadas nesta classe ocupacional quanto à paciência que é necessária na análise e julgamento dos processos e à sobrecarga de trabalho habitual, há de se considerar a seriedade da alta incidência do stress e da sintomatologia encontrados. A fim de desenvolver suas atividades de modo produtivo epreciso, pessoas com nível tão elevado de stress precisariam estar despendendo um esforço extraordinariamente alto. Sabe-se que o stress excessivo interferecom o raciocínio lógico, a memória ea habilidade de decisão (Lipp \& Malagris, 1995), deste modo, tornase de grande importância para a sociedade que trabalhos de prevenção do stress excessivo sejam realizados com os juízes da Justiça do Trabalho a fim de se garantir julgamentos que não reflitam as complicações do stress ocupacional. Qualquer profissão que seja capaz de criar tais níveis de stress em quem a exerça exige uma atenção 
especial por parte de profissionais da saúde e também por parte das associações de classe a fim de que o bemestar não só destes profissionais seja preservado, mas também para que a sociedade possa ser protegida das conseqüências que o stress excessivo pode acarretar. Há de se considerar a necessidade de uma avaliação profunda e identificação de possíveis mudanças das demandas que seinserem na Magistratura afim de quemelhores condições de trabalho sejam alcançadas por esta classe ocupacional. Que condições ambientais sejam reestruturadas dentro das organizações foi sugerido por Wright eCropanzano (2000) eN. Warren, Dillon, Morse, Hall eA. Warren (2000) como um modo de se reduzir o stress ocupacional a um nível nãotóxico. No caso presente, ficou clara a necessidade de uma análise detalhada quanto a que condições ocupacionais poderiam ser modificadas para garantir uma vida menos estressante para os juízes do trabalho.

Comparação entreo nível de stress dejuízes ejuízas

A grande maioria do entrevistados se encontravam na fase de resistência do stress (68\%). Esta fase, a intermediária no processo do stress, se caracteriza pelo cansaço físico e mental, dificuldades com a memória e uma maior vulnerabilidade a que doenças geneticamente programadas ou infecciosas ocorram devido à baixa no funcionamento do sistema imunológico. A produtividade pode também ser reduzida devido aos sintomas que aparecem. Se o organismo não consegue reverter o processo, a pessoa entra nafasedeexaustão quando ela fica quase queimpossibilitada de exercer suas funções.

Analisou-se a diferença entre juízes de acordo com 0 sexo e verificou-se, como pode ser visto na Figura 2, que

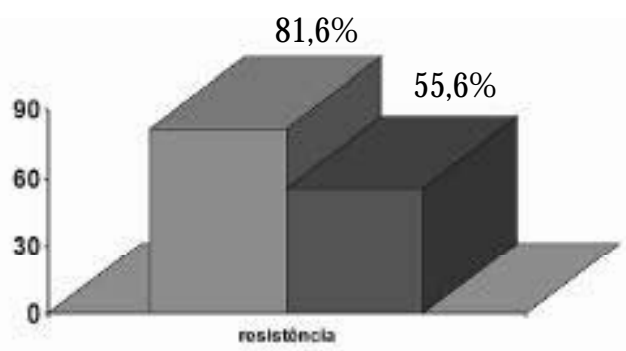

E feminino E masculino

Figura 2. Juízes com stress segundo o sexo.

aproximadamente $82 \%$ das juízas e $56 \%$ dos juízes do sexo masculino apresentavam stress mostrando uma diferença significativa entre os sexos $(t=2,24, p=0,02)$.

Pesquisas recentes tem revelado uma maior incidência de stress em mulheres brasileiras do que em homens (Lipp, Pereira, Floksztrumpf, Muniz \& Ismael, 1996), mas a diferença encontrada na amostra de juízes émuito grande significando que o stress é maior em juízas em função da ocupação exercida. Estedado, quetem inclusiveimplicações para o bem-estar das famílias, aponta para a necessidade de um melhor preparo emocional etreinamento em prevenção do stress para 0 exercício da Magistratura do Trabalho. Isto éespecialmenteimportante considerando-seque, deacordo com Vianna e colaboradores (1997), a maior concentração de juízas se encontra na Justiça do Trabalho. As diferenças em gênero encontradas merecem atenção em que não só a ocupação de juiz do trabalho poderia estar gerando um alto nível de stress para as mulheres entrevistadas, mas também as condições sociais que as levam a ter que despender um esforço maior para lidarem com as exigências da vida diária, quer no seio da família, quer no seu ambiente detrabalho. Dentreestesfatorescontribuintes paraum nível de stresspatológico pode seapontar o queéconhecido como a jomada tripla de trabalho que ocasiona uma redução no número de horas do sono e que, conseqüentemente, pode acarretar uma série de problemas de saúde (Lipp, 2001). A jornada tripla de trabalho se refere ao fato de que muitas mulheres além das funções regulares de esposa / mãe, exercem posições profissionais de destaque e após a família ir descansar ou dormir elas iniciam uma terceira jornada, cuidando de projetos ou tarefas que trouxeram para terminar em casa e que não puderam concluir até tarde por terem de cuidar da família. A terceira jornada se constitui em uma sessão de trabalho que se estende até altas horas da noite, em cujo caso a pessoa deixa de dormir o número de horas necessário para seu bemestar e pode entrar em um processo de agravamento do stress já existente ou desencadeamento do stress em si.

\section{Avaliação da qualidadedevida}

$\mathrm{Na}$ análise dos dados quanto à qualidade de vida, torna-seimportanteconsiderar que o instrumento utilizado (IQV) tem por objetivo avaliar as condições atuais do respondente em cada uma das quatro áreas pesquisadas (social, afetiva, profissional e saúde) que poderiam eventualmentelevar a problemas mais sérios. O IQV não objetiva diagnosticar problemas de saúde, por exemplo, mas sim as condições básicas que, se mantidas, poderão eventualmente favorecer o aparecimento de doenças. A Figura 3 revela que aproximadamente $80 \%$ dos avaliados mostraram indicações de dificuldades quanto à qualidade de vida na área da saúde, 41\% na área afetiva, 39\% na área profissional e $36 \%$ na área social. No total, o IQV indicou que a amostra de juízes pareceu se encontrar bastante prejudicada em termos de qualidade de vida, 0 que é de se esperar considerando a alta incidência de stress verificada no grupo. É preocupante, no entanto, verificar quea Magistratura, órgão detal importância para a sociedade 
no geral, esteja sendo exercida por profissionais que, devido às próprias pressões ocupacionais, se encontrem tão altamente prejudicados na área da saúde e na sua qualidade de vida, no sentido mais amplo. Os dados da presente pesquisa apontam para a necessidade prementede se avaliar as condições de trabalho tão difíceis com as quais se confrontam aqueles que atuam na área da Magistratura. Enquanto as condições atuais persistirem seria desejável que os componentes desta classe ocupacional recebessem treinamento no manejo adequado do stress emocional, a fim de que seus efeitos negativos possam ser reduzidos.

No quadrante social, um número maior de mulheres (71\%) tinha uma qualidade de vida boa em comparação

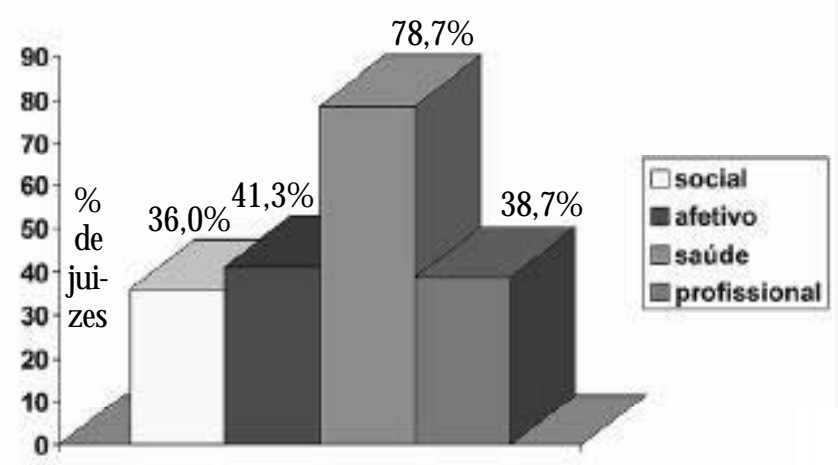

Figura 3. Juízes com má qualidade de vida.

com homens (58\%). Em todas as outras áreas os dados se invertem, e encontra-se sempre um número menor de mulheres usufruindo uma qualidade de vida adequada em comparação com o número mais elevado de homens com qualidade de vida melhor na área afetiva, na qual $67 \%$ dos juízes do sexo masculino parecem ter uma qualidade de vida boa em comparação com 50\% das mulheres. No quadrante profissional $70 \%$ dos homens tinham boa qualidade de vida em comparação com $55 \%$ das juízas. $\mathrm{Na}$ área da saúde, tanto homensquanto mulheres apresentaram hábitos de vida comprometedores de sua qualidade, sendo queenquanto a situação doshomensera ruim, com somente $28 \%$ apresentando sucesso, apenas $16 \%$ das mulheres revelaram ter boa qualidade de vida neste setor tão importante do funcionamento humano. As maiores áreas de dificuldades quanto à qualidade de vida se referiam à percepção de falta de segurança oferecida pelo trabalho, a não fazer uso de técnicas de relaxamento ou de exencícios físicos para controlar a tensão física e mental e sentir que não havia tempo suficiente para se dedicar à família.

Fontesdestressda atividadejudicante

No levantamento das causas do stress observado, quatro itens foram mencionados por quase a totalidade dos respondentes. Eles foram: 1) número de feitos a julgar, assinalado por $96 \%$ dos juízes; 2) salários que não correpondem às responsabilidades, ao desgaste e à importância do cargo $(95 \%), 3)$ falta de tempo para atualização (93\%) e 4) sacrifício do tempo dedicado à vida familiar esocial (92\%). As fontes destressmencionadas mais freqüentementepelosjuízes avaliados fazem parte daquelas identificadas por R. S. Lazarus e B. N. Lazarus (1994) como algumas das mais intensas na criação do nível de stress ocupacional. A importância da sobrecarga de processos a serem julgados, como uma poderosa fonte estressora, já havia sido ressaltada no tocante a juízes americanos por (Nalimi, 1992; Zimmerman, 1981). Outras fontes mencionadas foram solidão do ato dejulgar, conflitos entre valores profissionaise pessoais. Existeevidencianaliteratura deque estas fontes estão também presentes em Magistrados de outros países, conforme mencionado por Eells e Showalter (1994) quanto a conflitos de valores de juízes americanos e por Rogers e colaboradores (1991) quanto à solidão do ato de julgar nos juízes canadenses.

\section{Estratégiasdeenfrentamento maisutilizadas}

Foi interessanteverificar quea estratégia mais comumente utilizada por $69 \%$ dos juízes para fazer frente ao stress alto queexperimentam no exencício de sua profissão éconversar com o cônjuge ou alguém com quem esteja afetivamente ligado. Pensar nosfilhos foi outra estratégia assinalada pelos juízes casados (36\%) e passear foi a segunda mais escolhida pelos solteiros (53\%). A grande maioria (73\%) alegou não ter feito ou estar fazendo no momento psicoterapia, o que poderia ter sido considerada uma escolha como modo de lidar com a tensão do trabalho. Os dados revelam a importância de um vínculo afetivo na minimizacão do stress uma vez que conversas com alguém significativo é uma estratégiafreqüentementeutilizada pelosjúzes. Naturalmente isto também aponta para um possível nível elevado de stress em cônjuges de juízes, uma vez que o stress de uma pessoa pode criar níveis elevados de stress nas outras com quem convive.

\section{Correlação entreníveis destressequalidadedevida}

A influência do stress nos quadrantes da qualidade de vida foi avaliada através do uso da estatística Qui-quadrado. Verificou-se existir uma correlação significativa entre ter stress e o nível de qualidade de vida nas áreas da saúde (Qui-quadrado =6,63, $\mathrm{p} \varangle$,01) eafetiva (Qui-quadrado=6,10, $\mathrm{p}<0,01)$. Considerando-se que a estratégia mais utilizada pelos juízes para lidar com o stress é a conversa com alguém afetivamente importante, conclui-se que essas pessoas que dão apoio enfrentam uma situação difícil, pois além de darem 0 apoio não estão recebendo em troca a atenção e o tempo de convivência agradável com 
os parceiros, uma vez que o stress parece estar afetando a qualidade do relacionamento afetivo dos participantes.

\section{Conclusão}

O presente trabalho revelou que os juízes da Justiça do Trabalho avaliados percebiam sua profissão como uma das mais estressantes, semelhante ao de trabalhadores de minas e maior do que os de pilotos de avião. A porcentagem dos juízes com sintomas significativos de stress foi muito alta (71\%), sendo que o número de juízas com stress era significativamente maior do que o de seus colegas do sexo masculino exercendo as mesmas funções. Indicações foram levantadas de que a qualidade de vida dos respondentes talvez estivesse muito prejudicada em vários aspectos, principalmente nas áreas da saúde e afetiva. Os níveis de qualidade nestas duas áreas estavam significativamente correlacionados com o nível alto de stressdetectado. A fonte de stress mais freqüentemente mencionada foi o número excessivo de processos a julgar e a estratégia mais comumente utilizada para lidar com a tensão era a de conversar com o cônjuge ou alguém afetivamente importante. Os sintomas de stress mais encontrados foram sensação de desgaste e cansaço e tensão muscular. Só uma minoria fez ou fazia terapia, praticava exercícios físicos ou fazia uso de técnicas de relaxamento. Considerando o alto nível de stress do grupo esua qualidadedevida aparentemente prejudicada, uma das estratégias para lidar com a situação seria justamente a busca de uma terapia especializada em stress que lhes garantisse a aquisição de estratégias de enfrentamento. Porém, as medidas centradas no autodesenvolvimento, utilizadas como única estratégia para lidar com o stress, não são suficientes, pois os dados indicam uma necessidade grande de uma ação mais ampla de modificação das condições de trabalho a fim de sepromover uma redução dos estressores ligados ao exercício da Magistratura. Ações preventivas, de caráter mais amplo, são também indicadas no que se refere às juízas, uma vez queas condições estressantesinerentes ao seu cargo possivelmente sofram um efeito somatório com as condições sociais às quais estão sujeitas no seu dia-a-dia.

Os dados obtidos revelam um quadro preocupante no que toca a uma classe ocupacional que exerce a função fundamental de julgar processos trabalhistas quando a capacidade de raciocínio, o poder da lógica, a memória e a paciência são qualidades absolutamenteimprescindíveis para 0 adequado desenvolvimento dos processos e tomada de decisões justas. A saúde e a qualidade de vida desta classe trabalhista estão sofrendo o impacto de um nível destressexcessivamentealto eisto, por si só, já mereceria uma atenção especial das associações de classe e de profissionais da área da saúde a fim de que um trabalho de análise emudança das condições de trabalho nesta ocupação possam ser implementadas. Acrescente-se a esta preocupação humanista, outra, mais abrangente, queéo do impacto que tal nível de stress poderia, se não controlado, causar nos processos trabalhistas a serem julgados. Uma ação preventiva em forma de um treinamento na administração do stress é de fundamental importância para aqueles que se encontram no exercício da Magistratura da Justiça do Trabalho.

\section{Referências}

Albrecht, K. (1988). 0 gerente e 0 estresse (2a Ed.). Rio de Janeiro: Zahar.

Antoniazzi, A. S., Dell'aglio, D. D. \& Bandeira, D. R. (1998). O conceito de oping: Uma revisão teórica. Estudos de Psiologia, 3, 273-294.

Couto, H. A. (1987). Stress e qualidade de vida dos executivos. Rio de Janeiro: COP.

Covolan, M. (1989). 0 stress ocupacional do psiólogo dínioo: Seus sintomas, suas fontes e as estratégias utilizadas para ontrolá-lo. Dissertação de Mestrado Não-publicada, Instituto de Psicologia, Pontifícia Universidade Católica de Campinas. Campinas, São Paulo.

Curcio, M. A. (1991). Estudo do estresse e qualidade de vida de uma amostra de pacientes onoológioos. Dissertação de Mestrado Não-publicada, Instituto de Psicologia, Pontifícia Universidade Católica de Campinas. Campinas, SP.

Di Martino, V. (1992). Occupational stress: A preventive approach. Conditons of Work Diget, 11 (2), 3-22.

Eells, T. D. \& Showalter, D. (1994). Work-related stress in American trial judges. Bulletin American Academy of Psychiatry Law, 22 (1), 71-83.

Everly, G. S. (1995). Innovations in disaster and trauma Psychology. Maryland: Chevron.

Folkman, S. \& Lazarus, R. S. (1985). If it changes it must be a process: Study of emotion and coping during three stages of a college examination. Journal of Personality and Social Psychology, 48, 150-170.

Fontana, D. (1991). Estrese. São Paulo: Saraiva.

França, H. H. (1987). A Síndrome de burnout. Revista Brasileira de Medicina, 44, (48), 197.

Girdano, D. A. \& Everly, G. S. (1979). Controling stress and tension. Englewood Cliffs: Prentice Hall.

Holmes, T. H. \& Rahe, R. K. (1967). The social readjustment rating scale. Journal of Psychosomatic Research, 11, 213-218

Kaplan, R. M. (1995). Quality of life, resource allocation and the U.S. health-care crisis. Em J. E. Dimsdale \& A. Baum (Orgs.), Quality of life in behavioral medicine research (pp.3-30). Hilldsdale, New Jersey: Lawrence Erlbaum.

Kyriacow, C. \& Sutcliffe, J. (1981). Social support and occupational stress among school teachers. Educational Studies, 7, (1), 55-60.

Lazarus, R. S. \& Lazarus, B. N. (1994). Passion and reason: Making sense of our emotions. New York: Oxford University Press.

Lipp, M .E. N. (1984). Stress e suas implicações. Estudos de Psiologia, 3, 5-19.

Lipp, M. E. N. (1997). Pesquisas sobre stress no Brasil. Campinas, SP: Papirus.

Lipp, M. E. N. (2001). 0 stress e a beleza da mulher. São Paulo: Connection.

Lipp, M. E. N. \& Guevara, A. J. H. (1994). Validação empírica do Inventário de Sintomas de Stress. Estudos de Psiologia, 11 (3) 42-49.

Lipp, M. E. N. \& Malagris, L. E. N. (1995). O manejo do stress. Em B. Range (Org.), Psicoterapia comportamental e oognitiva: Pesquisa, prática, aplicaōes e problemas. (pp. 279-292). Campinas: Editorial Psy II.

Lipp, M. E. N., Pereira, I. C., Floksztrumpf, C. Muniz, F. \& Ismael, S. C (1996). Diferenças em nível de stress entre homens e mulheres na Cidade de São Paulo [Resumos]. Em Pontifícia Universidade Católica de Campinas (Org.), Anais do I Simpósio sobre Stress e suas Implicaọes. Campinas: PUC-Campinas, p.122. 
Lipp, M. E. N. \& Rocha, J. C. (1995). Stress, hipertensão equalidadedevida. Campinas: Papirus.

Lipp, M. N., Romano, A. S. P. F., Covolan, M. A. \& Nery, M. I. (1986). Como enfrentar 0 stress São Paulo: Ícone.

Lipp, M. E. N., Sassi, L. \& Batista, I. (1997). Stress ocupacional na equipe cirúrgica. Cadernos de Pesquisa, III (1-2), 57-64.

Maciel, S. V. (1997). Atleta juvenil feminina: Correlação entre características psicológicas, stress e lesões osteomusculares. Em M. E. N. Lipp (Org.), Pesquisas sobre stress no Brasil. (pp.211-224). Campinas, SP: Papirus.

Mancia, G. \& Parati, G. (1987). Reactivity to physical and behavioral stress and blood pressure variability in hypertension. Em S. Julius \& D. R. Bassett (Orgs), Behavioral factors in hypertension (pp.104-122). New York: Elsevier.

Malagris, L. E. N. (1992). Stresseúloeras gastroduodenais Interaỹoes dínioo-psiológicas. Dissertação de Mestrado Não-publicada, Instituto de Psicologia, Pontifícia Universidade Católica de Campinas. Campinas, SP.

Myers, D. (1995). Worker stress during long term disaster recovery efforts. Em G. S. Everly (Org.), Innovationsin disaster and trauma psychology (pp.2344). Maryland: Chevron.

Nacarato, A. B. (1995). Stress no idoso: Efeitos diferenciais da ocupação profissional. Dissertação de Mestrado Não-publicada, Instituto de Psicologia, Pontifícia Universidade Católica de Campinas. Campinas, SP.

Nalimi, J. R. (1992). 0 juiz e 0 aøesso à justiça. Rio de Janeiro: Revan.

Perlman, S. B. \& Hartman, E. A. (1982). Burnout: Sumary and future research. Human Relations, 35, 283-305.

Proença, I. M. (1998). Stress ocupadional equalidade devida dejornalistas da mídia impressa diária. Dissertação de Mestrado Não-publicada, Instituto de Psicologia, Pontifícia Universidade Católica de Campinas. Campinas, $\mathrm{SP}$

Proença, I. M., Bortoletto, V. \& Lipp, M. E. N. (1996). Stress e qualidade de vida de executivos brasileiros [Resumos]. Em Pontifícia Universidade Católica de Campinas (Org.), Anais, I Simpósio sobre Stress e suas Implicações (p.107). Campinas: PUC-Campinas.

Reinhold, H. H. (1997). Stress ocupacional no professor. Em M. E. N. Lipp (Org.), Pesquisas sobre stress no Brasil (pp. 169-194). Campinas, SP: Papirus.

Rogers, J. M, Freemand, S. J. \& LeSage, P. (1991). The occupational stress of judges. Canadian Journal of Psychiatry, 36, 317-322

Romano, A. S. P. F. (1989). Levantamento dasfontes de stress ocupacional de soldados da polída militar eo nível destresspor ela criado: Uma proposta decurso decontrole de stress espećfico para a polícia militar. Dissertação de Mestrado Nãopublicada, Instituto de Psicologia, Pontifícia Universidade Católica de Campinas. Campinas, SP.

Savoia, M. G., Santana, P. R. \& Mejias, N. P. (1996). Psiologia USP, 7, 183-201.

Selye, H. (1956). The stress of life. NY: McGraw-Hill.
Showalter, C. R. \& Martell, O. L. (1985). Personality, stress and health in American judges. Judicature, 69, 82-87.

Silva, A. C. A. (1992). Estresse, estressores, equalidadedevida debancários: Um estudo exploratório œm uma amostra de funcionários do Banœ do Brasil. Dissertação de Mestrado Não-publicada, Instituto de Psicologia, Pontifícia Universidade Católica de Campinas. Campinas, SP.

Soares, D. S. M. (1990). 0 stress do executivo brasileiro: Diferenças e similaridades entre homens e mulheres Dissertação de Mestrado Não-publicada, Instituto de Psicologia. Pontifícia Universidade Católica de Campinas. Campinas, SP.

Suran, B. G. (1982). Psychological disability among judges and other professionals: Some causes and cures. Judicature, 66, 185-193.

Teicher, M. H., Ito, Y., Glod, C. A., Schiffer, F. \& Gelbard, H. A. (1996). Neurophysiological Mechanisms of stress. Em C. R. Pfeffer (Org.), Severe stress and mental disturbanœin children (pp. 59-84). Washington, D.C.: American Psychiatric Press.

Vianna, L. W, Carvalho, A. R., Melo, P. C. M. \& Burgos, B. M. (1997). Corpo e alma da Magistratura Brasileira (2 a. Ed.). Rio de Janeiro: Revan.

Villar, M. A. L. (1992, maio). Working environment at an emergency assistance hospital. Trabalho apresentado no International Symposium on Work-related Diseases: Prevention and Health Promotion. Linz, Austria.

University of Manchester Institute of Science and Technology (1987). Understanding stres Part II, London: HMSO

Warren, N., Dillon, C., Morse, T., Hall, C. \& Warren, A. (2000). Biomechanical, psychosocial, and organizational risk-factors for WRMSD: Populationbased estimates from the connection upper-extremity surveillance projetct (CUSP). Journal of Ocaupational Heelth Psychology, 5(1), 164-181.

Wright, T. A. \& Cropanzano, R. (2000). The Role of Organizational Behavior in Occupational Health Psychology: A view as we approach the Millenium. Journal of Ocaupational Health Psychology, 5(1), 5-10.

Zakir, N. S. (2001) Enfrentamento epercepcão de controlabilidadepessoal esituacional nas reações de stress. Tese de Doutorado Não-publicada, Instituto de Psicologia, Pontifícia Universidade Católica de Campinas. Campinas, SP.

Zimmerman, I. M. (1981). Stress: What it does to judges and how it can be lessened. Judges Joumal, 4, 18-22.

\author{
Sobre os autores \\ Marilda Emmanuel Novaes Lipp éDoutora eProfessoratitular daPontifíciaUniversidadeCatólica \\ deCampinas. \\ Maria do Sacramento Tanganelli é Doutora em Psicologia eatua no Centro Psicológico de \\ Controle do Stress.
}

Recebido: 22/11/2001

Revisado: 29/01/2002

Última Revisão: 04/07/2002

Aœite Final: 05/07/2002 


\section{Anexo A}

\section{Inventário de Fontes Estressoras na Atividade Profissional do Juiz do Trabalho (IFSJ)}

\section{Sr. Magistrado:}

Por favor responda às perguntas abaixo de acordo com sua percepção do impacto que os eventos mencionados exercem em sua vida.

1.0 exercício de sua profissão é estressante?

2.Em uma escala de 1 a 10 sendo 10 extremamente estressante, que nota seria aplicada ao stress ocupacional ao qual está sujeito?

3.Usando como referência o início de sua carreira e o tempo decorrido no exercício da profissão quando o stress foi mais intenso?

4.Considerando a si próprio como referencial, o que mais o estressa no exercício da profissão?

5. Em uma escala de 1 a 10 considerando 10 como extremamente estressante, que nota de stress daria aos itens abaixo:

Contato com colegas juízes

Contato com advogados

Contato com empresas enquanto parte de processos

Contato com funcionários enquanto parte de processos

Contato com equipe de apoio

Contato com o processo em si

Desempenho próprio nas audiências

Exigências excessivas da sociedade

Premência de tempo nos processos

Falta de reconhecimento pelo público

Falta de reconhecimento pelas outras autoridades

As próprias emoções quanto aos casos que julga

Valores próprios incompatíveis com as decisões exigidas

Ter pouco poder 
548

Marilda E. Novaes Lipp \& M. Sacramento Tanganelli

Ter poder excessivo

Ter controle da situação que julga

Não ter controle suficiente sobre os processos

O impacto que tem na sociedade

Não ter impacto suficiente na sociedade

Sentir-se isolado ao tomar decisões

Necessitar trabalhar na própria residência nos processos

Sentir culpa quanto às decisões tomadas

Sentir frustração quanto aos processos

Expectativas próprias não preenchidas

Limitações impostas em sua vida pessoal devido à profissão

Outros estressores. Favor indicá-los e colocar a nota de stress para cada um. 